\title{
PARTICIPATORY FORMS OF DIGITAL GOVERNANCE AND PEOPLE-POWERED SERVICES
}

\author{
Gheorghe H. Popescu, ${ }^{1, a,{ }^{*},}$ Kenneth Creager ${ }^{2, b}$ \\ ${ }^{1}$ Faculty of Banking and Finance, Dimitrie Cantemir Christian University, Splaiul Unirii 176, \\ Bucharest 030134, Romania \\ ${ }^{2}$ European Center for Economic Performance, CSA, 30-18 50 ${ }^{\text {th }}$ Street, Woodside, New York City, \\ 11377, United States \\ agheorghe.h.popescu@ gmail.com, ${ }^{\mathrm{b}}$ creager@aa-er.org \\ *Corresponding author
}

Cite as: Popescu, G.H., Creager, K. (2017). Participatory forms of digital governance and peoplepowered services, Ekonomicko-manazerske spektrum, 11(2), 45-52.

Available at: dx.doi.org/10.26552/ems.2017.2.45-52

\begin{abstract}
Relying on recent research on how governments and individuals activate in a digital setting, leaving electronic traces that bring about immense volumes of data about themselves and any interplays they have, we first analyze the broader theoretical arguments that prove that information and knowledge create capacity for cutting edge, performance, and the sharpness to adjust to a swiftly altering environment. We advance primary empirical research for the main case study that clarifies that there are cultural obstacles to employing social media and adopting the digital timestream, and advancing the data science abilities required to obtain public usefulness from big data. We use meta-analysis to inspect the evidence that Internet and mobile-based digital technologies favour co-production and cocreation: at the separate level, most individuals handle their matters with government as they do with their bank; at the shared level, co-production may entail a type of crowdsourcing, where individuals inform governments of non-necessity issues in proximities, while at the strategy level, co-production advances so as to achieve co-creation, individuals employing the government as stage notion to co-create both strategy and services. Based on this evidence, we exemplify arguments that governments are unsuccessful in taking advantage of the affordances of big data, whereas individuals are powerless to connect with government digitally as they do with companies or social undertakings.
\end{abstract}

Keywords: citizen-centric, digital, governance, service, delivery

JEL Classification: G18, H11, I28

\section{Introduction}

Relying on recent research (Dunleavy \& Margetts, 2015) on how governments and individuals activate in a digital setting, leaving electronic traces that bring about immense volumes of data about themselves and any interplays they have, we first inspect the broader theoretical arguments that clarify that information and knowledge create capacity for cutting edge, performance, and the sharpness to adjust to a swiftly altering environment. (Blackman, 2017; Marland et al., 2017) Nearly all governments are dependent on a significant digital manifestation and an intricate arrangement of wide-ranging information systems for regulatory processes and policy-making (Machan, 2016, A) that influence the entire framework within which strategy and service distribution options are constituted, either 


\section{Participatory Forms of Digital Governance and People-Powered Services \\ Authors: Gheorghe H. Popescu, Kenneth Creager}

furthering novelty or limiting policy choices. An absence of blueprint is the main obstacle hampering early-stage entities (Vasile \& Androniceanu, 2016) from utilizing digital trends to the fullest extent. As early-stage entities advance, an absence of strategy dies down (Bauder, 2016) and confines cover portfolio handling, funding, and managing cyber security. The possible effect of a digital approach is chiefly regulated by its aim and reach. Digital blueprints at early-stage entities highlight a practical target. (Decuypere, 2016; Kalbaska et al., 2017) Governments strive to equal an ever more technologically sagacious community, familiar with collaboration through social networks and electronic forums (Madsen \& Wu, 2016) which have immediately acquired more confidence online than the stereotypical proposals of government bureaucracies. (Peng, 2017) Digital leaders employ a well-defined digital approach associated with a culture and leadership (Hellman \& Majamäki, 2016) stabilized to stimulate the alteration. An entity's digital advancement is impacted considerably by its digital approach. (Eggers \& Bellman, 2016)

\section{Literature review}

Leaders who master digital orientations and technologies tend to supply organizational backing (Peters \& Besley, 2016) to their personnel to assist them strengthen digital skills, in comparison with individuals who are deficient in that awareness. Less digitally sophisticated agencies fail regarding the capacity to visualize mentally how digital technologies may affect the business. Citizen demands are more outstanding (Tulloch, 2016) as an agency ascends the advancement curve. An intense attention on employing digital technologies to enhance the citizen practice (Androniceanu \& Ristea, 2014) assists maturing entities in boosting service distribution. Digitally advancing government entities are typified by a culture that facilitates digital evolution, bolstering innovation, furthering collaborative labor settings, and preserving a constructive position toward risk-taking. (Holeman et al., 2016; Dawes, 2009) Digital technologies are instrumental in assisting maturing entities attain strategic objectives. (Kourtit et al., 2017; Myeong et al., 2014) The relevance that entities establish on employing digital technology to enhance cutting edge and decision making differs by digital maturity degree. The exponential alterations that stimulate digital evolution confront the conventional patterns of leadership (Popescu Ljungholm, 2016) and governance. Laborers in digitally maturing entities are more expectant in their leaders' capacity to handle the digital business. Entities at higher degrees of advancement constantly have leaders with the expertise and grasp (Fisher, 2016) to manage the digital evolution mechanism. The ubiquity or nonappearance of a digitally experienced leadership (Androniceanu, 2014) is instrumental in whether the entity begins a course of action to upskill its personnel. (Eggers \& Bellman, 2016)

\section{Methodology}

Based on this evidence, we exemplify Dunleavy \& Margetts (2015)'s argument that governments are unsuccessful in taking advantage of the affordances of big data, whereas individuals are powerless to connect with government digitally as they do with companies or social undertakings. We develop primary empirical research for our case study that indicates that there are cultural obstacles to employing social media and adopting the digital timestream, and advancing the data science abilities required to obtain public usefulness from big data. Internet and mobile-based digital technologies favor co-production and co-creation: at the separate level, most individuals handle their matters with government as they do with their bank (Wilkinson \& Kemmis, 2015); at the shared level, co-production may entail a type 
of crowdsourcing, where individuals inform governments of non-necessity issues in proximities, while at the strategy level, co-production advances so as to achieve co-creation, individuals employing the government as stage notion to co-create both strategy and services. (Dunleavy \& Margetts, 2015) Numerous public entities strive to subsidize essential citizen services and digital proposals, despite the fact that digital evolution is a path to considerable expense savings. Leaders attempting to stimulate transformation confront challenging priorities. (Dunleavy et al., 2006) Public entities that effectively handle their objectives (Brown, 2016) are likely to have consistent, realistic approaches and well-defined business cases. Excepting insubstantial financial backing and too numerous conflicting first concerns, advancing entities indicate security as a critical obstacle. For early-stage entities, the unavailability of a long-term approach (Grant, 2016), associated with an absence of apprehension of digital orientations, is a decisive impediment. While approach constitutes the ground of the transformation mechanism, leaders might not comprehend its relevance. Entities with a well-defined and consistent approach are more digitally developed, more thoroughly prepared to react to chances and menaces, having a culture that cultivates cutting edge and collaboration. (Eggers \& Bellman, 2016)

\section{Empirical data and analysis}

Following Eggers and Bellman (2016), our meta-analysis combines data from 214 papers identified in the Web of Science as covering the participation of individuals in the co-creation of digital services, the degree of organizational challenge in handling the transition to digital in the sphere of culture (Selth, 2016), leading determinants of digital transformation, and the utilization of open source technology to provide digitally improved services. The essential position is that the internet brought into government an organizational culture that functions in opposition to the steadiness of operations (Hurd, 2016) and interferes with the proposal that procedures may be digitally embedded. If citizens network with government via social media platforms, consequently there are more opportunities (Eacott \& Evers, 2015) that they may collaborate with government in co-creation. Computers operate as a channel for novel kinds of professional connections and economic requirements (Lucas, 2016) on the activity of government. (Dunleavy \& Margetts, 2015) Current cultural norms frequently require endeavors to embed the precepts of digital (user target, open performance, and active advancement) in government entities. Nearly all public sector entities deal with the cultural matters of digital evolution. The public sphere should increase the digital expertise of both laborers who address digital evolution (Siekelova et al., 2017) and those who affect it. Individuals who are at advanced in digital evolution should cooperate closely with staffing partners to attract the appropriate type of digital expertise. A digital attitude is distinct from how nearly all entities, particularly in the public sphere, deal with the world, concerning views about stakeholders (Newton \& Riveros, 2015), introducing goods and services, and manners of labor. (Eggers \& Bellman, 2016) (Figures 1-8) 


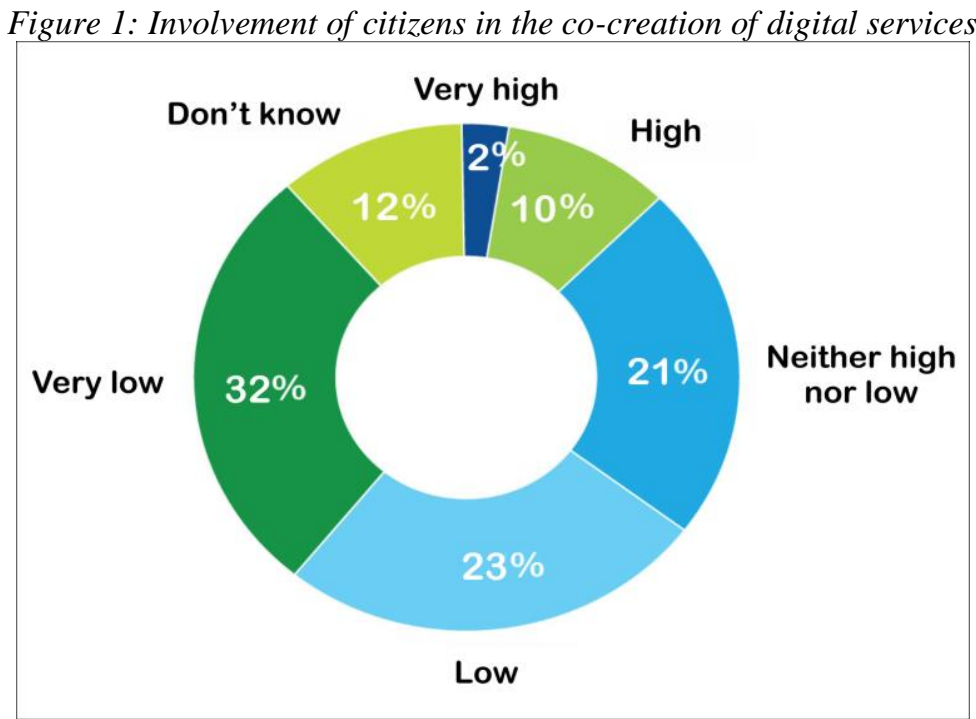

Source: Deloitte University Press and our calculations

Figure 2: The extent of organizational challenge to manage the transition to digital in the area of culture

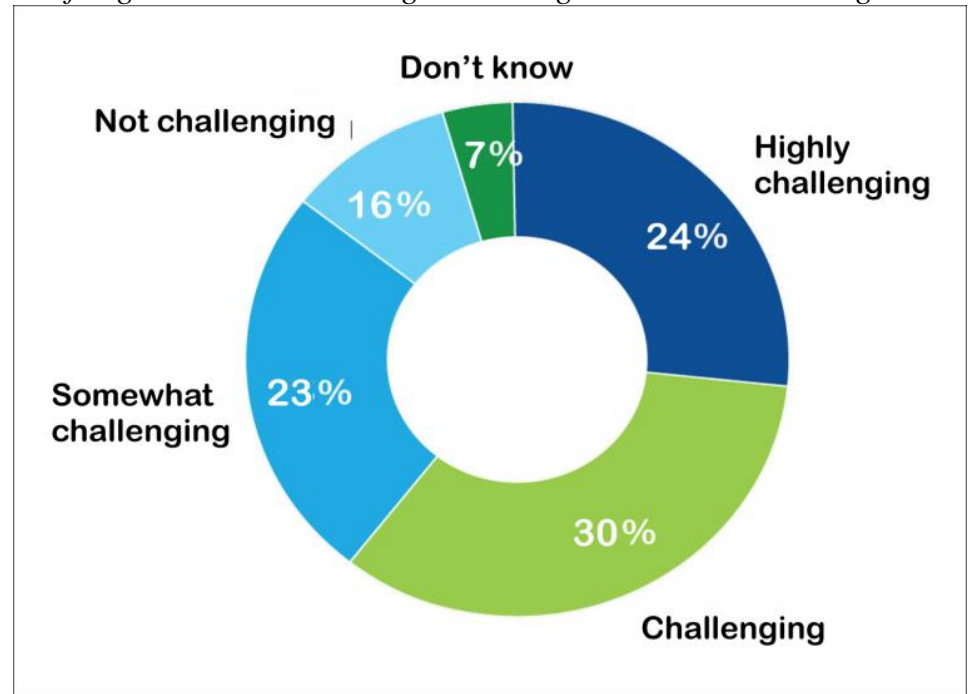

Source: Deloitte University Press and our calculations

Figure 3: Primary drivers of digital evolution

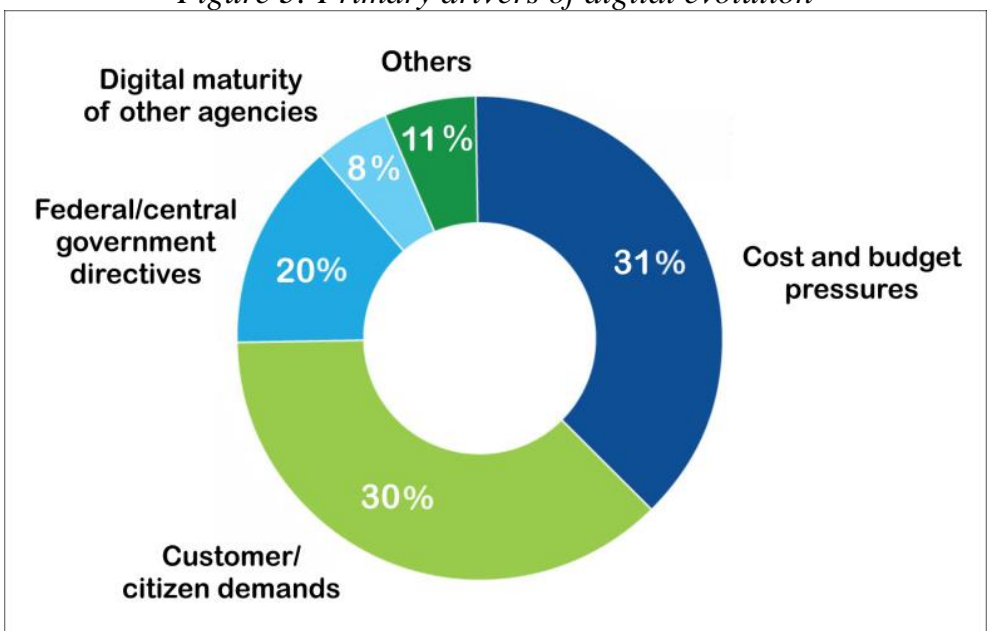

Source: Deloitte University Press and our calculations 
Figure 4: Use of open source technology to deliver digitally transformed services

ource: Deloitte University Press and our calculations

Figure 5: \% of workers who ever use social media platforms to...

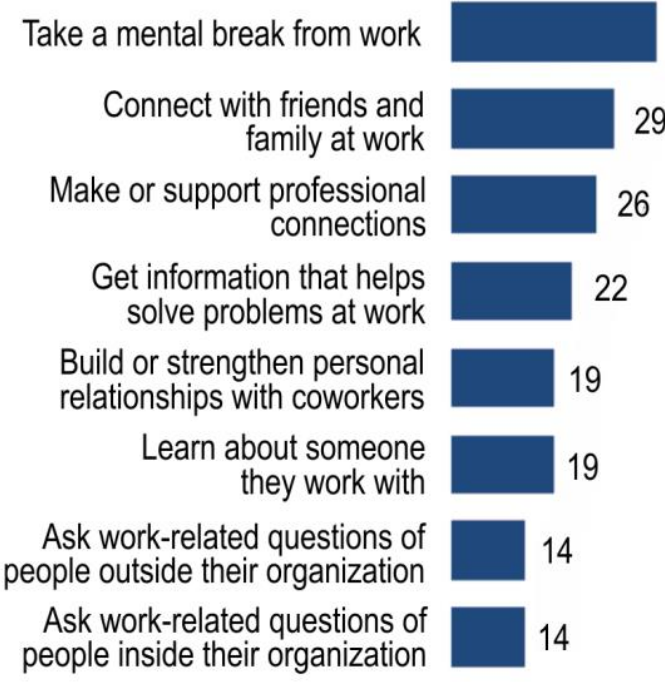

Source: Pew Research Center. Survey conducted by us February 8-17, 2017

Figure 6: Improved communication and collaboration through social technologies: \% of average workweek

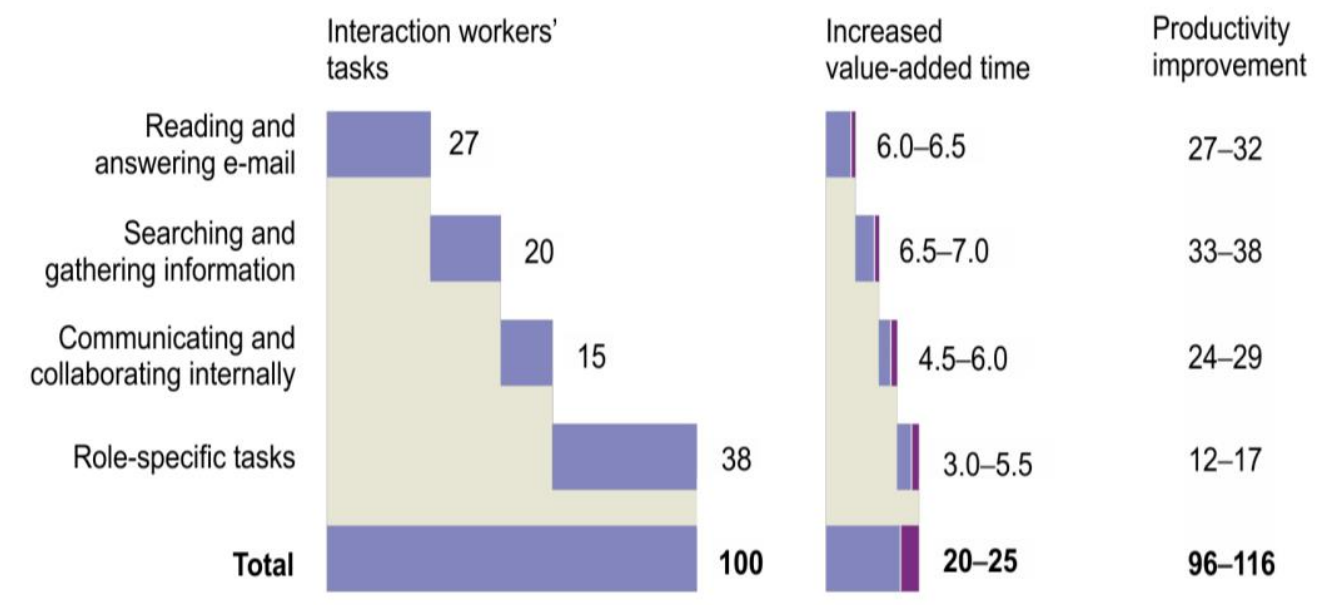

Source: International Data Corporation, McKinsey Global Institute analysis, and our estimations 
Figure 7: Returning to churning: Percent change in monthly level of hiring, separations and voluntary quits

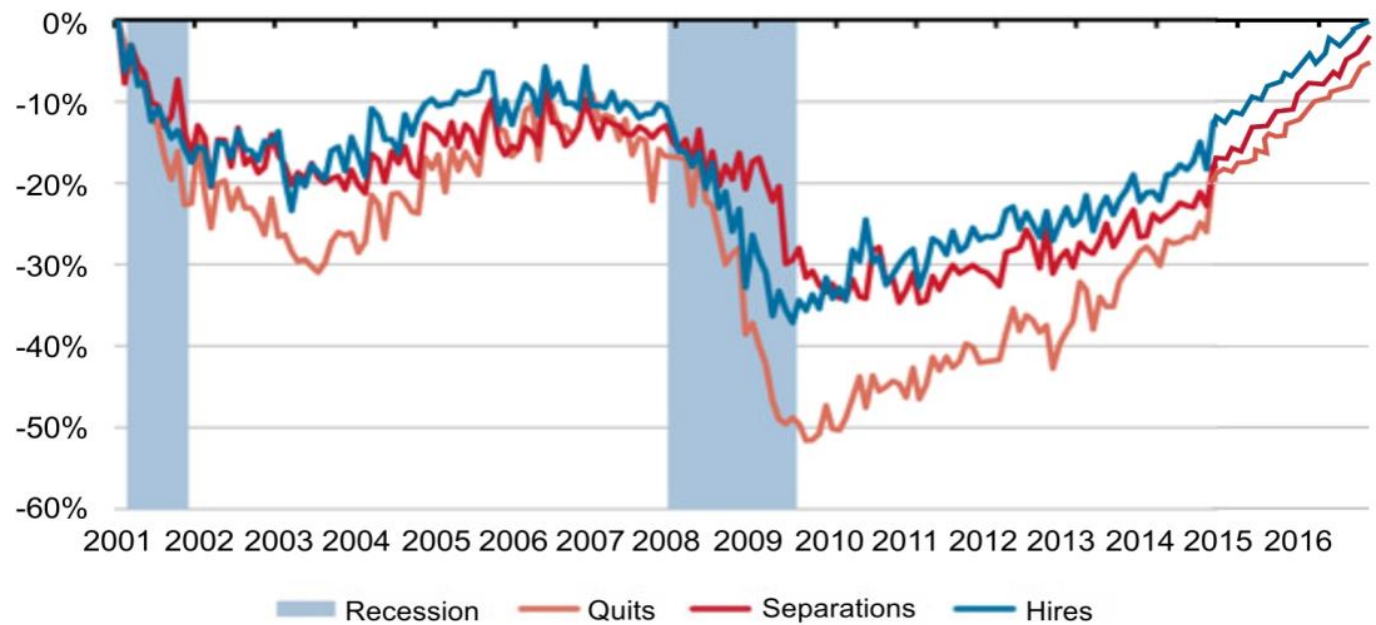

Source: Labor Department, WSJ.com, and our estimations

Figure 8: Comings and goings: Monthly rate of job openings, hires, and quits, seasonally adjusted

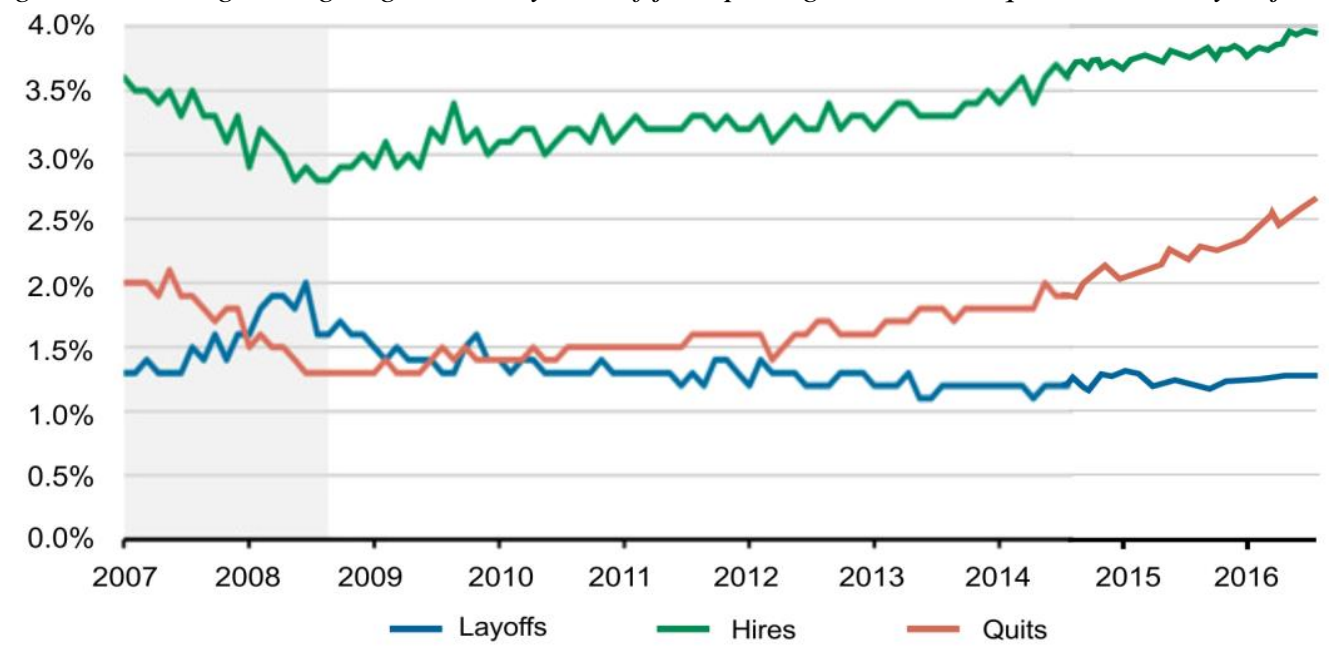

Source: Labor Department, WSJ.com, and our estimations

\section{Results and discussion}

To address digital evolution (Androniceanu, 2012), public sector entities should access a powerful and newfangled technology marketplace. Acquisition and commercial approaches should alter radically to harmonize digital evolution. Entities throughout spheres and roles confront cultural obstacles (Williams et al., 2016) in their digital progress. Citizen needs and expense and budget constraints are the most outstanding determinants of digital evolution. Government entities should work meticulously with citizens to establish a user-centric digital practice (Machan, B, 2016): they are likely to come to grips with guaranteeing internal buy-in and not with delivering to user demands. Even for entities that claim citizen need is the leading determinant of digital evolution (Mihăilă et al., 2016), the proportion considerably grappling with users to co-produce digital services is rather low. (Eggers \& Bellman, 2016)

\section{Conclusions}

Unceasing digital transformation may identify public entities that strive as the setting alters around them (Chitpin \& Jones, 2015), whereas others may exploit all that digital evolution 
can provide and thus prosper. Preceding the rise of digital technologies, novel strategies may be evaluated via all-encompassing investigation (Friedman et al., 2016), investment judgments may be established on cost-benefit direction, and the end intention of nearly all blueprints is a definite point. For public sphere agencies worldwide, the pecking orders and governance arrangements are frequently more noticeable than in the private sphere. Public sector strategies to acquisition are justifiably fashioned to check that public resources are allocated adequately. A shared series of matters and a common set of obstacles (Bolton, 2016) are hindering transformation: culture, acquisition, personnel, leadership, and approach that are not maintaining the proper rhythm or are ill-prepared (Mihăilă, 2016) for a technologically cutting-edge, citizen-centric epoch. Efficacious public entities are to be more adjustable to the fashionable digital period, re-conceptualizing their services and unceasingly remodeling the manner they get involved with users. (Eggers \& Bellman, 2016)

\section{Note}

A version of this article was previously presented at the $17^{\text {th }}$ International Scientific Conference Globalization and Its Socio-Economic Consequences, University of Zilina, 4-5 October 2017.

\section{References}

Androniceanu, A. (2012). Key issues related to the human resources management nowadays. Proceedings of the $6^{\text {th }}$ International Management Conference: Approaches in Organisational Management. Bucharest, Romania, 221-230.

Androniceanu, A. (2014). Research on management capacity of medical units for addicts to deliver quality services in time of crisis. Revista de Cercetare si Interventie Sociala, 47, 78-104.

Androniceanu, A. and Ristea, B. (2014). Decision making process in the decentralized educational system. Procedia Social and Behavioral Sciences, 149, 37-42.

Bauder, H. (2016). Understanding Europe's refugee crisis: A dialectical approach. Geopolitics, History, and International Relations, 8, 64-75.

Blackman, C. (2017). Digital policy, regulation and governance, Digital policy regulation and governance, vol. 19(1), 1-1.

Bolton, J. (2016). Predicting and managing demand in social care. American Journal of Medical Research, 3 , 152-187.

Brown, J.A. (2016). The new 'southern strategy:' Immigration, race, and 'welfare dependency' in contemporary US Republican political discourse. Geopolitics, History, and International Relations, 8, 22-41.

Chitpin, S. and Jones, K. (2015). Leadership in a performative context: A framework for decision-making. Educational Philosophy and Theory, 47, 387-401.

Dawes, S.S. (2009). Governance in the digital age: A research and action framework for an uncertain future, Government Information Quarterly, 26(2), 257-264.

Decuypere, M. (2016). Diagrams of Europeanization: European education governance in the digital age, Journal of Education Policy, 31(6), 861-872.

Dunleavy, P. and Margetts, H. (2015). Design principles for essentially digital governance. 111th Annual Meeting of the American Political Science Association. San Francisco, USA.

Dunleavy, P., Margetts, H., Bastow, S., and Tinkler, J. (2006). New public management is dead - long live digital-era governance, Journal of Public Administration Research and Theory, 16(3), 467-494.

Eacott, S. and Evers, C. (2015). New frontiers in educational leadership, management and administration theory. Educational Philosophy and Theory, 47, 307-311.

Eggers, W.D. and Bellman, J. (2016). The Journey to Government's Digital Transformation. Westlake, TX: Deloitte University Press.

Fisher, N. (2016). Midwest diagnosis: Immigration reform and the healthcare sector. American Journal of Medical Research, 3, 84-114.

Friedman, D., Friedman, H.H., and Friedman, L.W. (2016). US healthcare: A system in need of a cure. American Journal of Medical Research, 3, 125-141. 


\section{Participatory Forms of Digital Governance and People-Powered Services \\ Authors: Gheorghe H. Popescu, Kenneth Creager}

Grant, S. (2016). Employer sponsored fertility preservation: Debating institutional promotion of reproductive procrastination or choice. Journal of Research in Gender Studies, 6, 120-145.

Hellman, M. and Majamäki, M. (2016). Ordinary men with extra-ordinary skills? Masculinity constructs among MMORPG-gamers. Journal of Research in Gender Studies, 6, 90-106.

Holeman, I., Cookson, T.P., and Pagliari, C. (2016). Digital technology for health sector governance in low and middle income countries: a scoping review, Journal of Global Health, 6(2), 020408.

Hurd, H.M. (2016). The innocence of negligence. Contemporary Readings in Law and Social Justice, 8, 48-95.

Kalbaska, N., Janowski, T., Estevez, E. and Cantoni, L. (2017). When digital government matters for tourism: A stakeholder analysis, Information Technology \& Tousrism, 17(3), 315-333.

Kourtit, K., Nijkamp, P., and Steenbruggen, J. (2017). The significance of digital data systems for smart city policy, Socio-Economic Planning Sciences, 58, 13-21.

Lucas, R.E.B. (2016). Integral migration in developing economies: An overview of recent evidence. Geopolitics, History, and International Relations, 8, 159-191.

Machan, T.R. (2016 A). Individualism in the right key. Contemporary Readings in Law and Social Justice, 8, 11-19.

Machan, T.R. (2016, B). The morality of gregarious egoism. Contemporary Readings in Law and Social Justice, 8, 7-29.

Madsen, E.S. and Wu, Y. (2016). Low R\&D efficiency in large pharmaceutical companies. American Journal of Medical Research, 3, 141-151.

Marland, A., Lewis, J.P., and Flanagan, T. (2017). Governance in the age of digital media and branding, Governance-An International Journal of Policy Administration and Institutions, 30(1), 125-141.

Mihăilă, R. (2016). Is the decrease in the gender wage gap the principal driver of the sustained rise in female labor market participation? Journal of Research in Gender Studies, 6, 146-152.

Mihăilă, R., Popescu, G.H. and Nica, E. (2016). Educational conservatism and democratic citizenship in Hannah Arendt. Educational Philosophy and Theory, 48, 915-927.

Myeong, S., Kwon, Y., and Seo, H. (2014). Sustainable E-Governance: The relationship among trust, digital divide, and e-government, Sustainability, 6(9), 6049-6069.

Newton, P. and Riveros, A. (2015). Toward an ontology of practices in educational administration: Theoretical implications for research and practice. Educational Philosophy and Theory, 47, 330-341.

Peng, Y.Z. (2017). Affective networks: How WeChat enhances Tencent's digital business governance, Chinese Journal of Communication, 10(3), 264-278.

Peters, M.A. and Besley, T. (2016). 'We never expel a foreigner' - Globalism, interconnectivity and the experiment of the open society. Geopolitics, History, and International Relations, 8, 112-126.

Popescu Ljungholm, D. (2016). The role of work organizations in the social construction of gender. Journal of Research in Gender Studies, 6, 269-275.

Selth, A. (2016). The road to Mandalay: Orientalism, 'Burma girls' and Western music. Journal of Research in Gender Studies, 6, 159-191.

Siekelova, A., Kliestik, T., Svabova, L., Androniceanu, A. and Schonfeld, J. (2017). Receivables management: The importance of financial indicators in assessing the creditworthiness. Polish Journal of Management Studies, 15, 217-228.

Tulloch, L. (2016). The transnational state, neoliberalism and environmental education policy: A New Zealand case study. Contemporary Readings in Law and Social Justice, 8, 170-195.

Vasile, O. and Androniceanu, A. (2016). Dynamics of migration in Romania and management of financing instruments. European Proceedings of Social and Behavioural Sciences. Iasi, Romania, pp. 1059-1067.

Wilkinson, J. and Kemmis, S. (2015). Practice theory: Viewing leadership as leading. Educational Philosophy and Theory, 47, 342-358.

Williams, J. C., Phillips, K. W. and Hall, E. V. (2016). Tools for change: Boosting the retention of women in the STEM pipeline. Journal of Research in Gender Studies, 6, 11-75. 